Z. Klin. Chem. Klin. Biochem.

12. Jg. 1974 , S. $171-175$

\title{
Änderung der Zinkkonzentration im Serum bei verschiedenen Stoffwechselsituationen
}

\author{
Von M. Persigehl, A. Höck, K. Kasperek, E. Land und L. E. Feinendegen \\ Institut für Medizin, Kernforschungsanlage Jülich GmbH, Jülich, West Germany
}

(Eingegangen am 21. Dezember 1973/28. Februar 1974)

\begin{abstract}
Bei gesunden Probanden wurde die zeitliche Änderung der Serum-Zinkkonzentration unter Ruhe und körperlicher Belastung, nach oraler Glucose- und Proteinzufuhr sowie nach intravenöser Glucose- und Sekretininjektion mit Hilfe der instrumentellen Neutronenaktivierungsanalyse bzw. der Atomabsorptionsspektroskopie gemessen. Trockengewicht oder Proteingehalt des Serums wurden mitbestimmt.

Bei Ruhelage fällt die Serum-Zinkkonzentration ab, während sie bei körperlicher Belastung ansteigt. Nach Glucosezufuhr und vor allem nach Proteingabe wird der Serum-Zinkgehalt vermindert, nach Sekretininjektion findet sich dagegen eine Erhöhung. Die Daten zeigen, daß die Serum-Zinkkonzentration nicht als konstanter Wert betrachtet werden darf und daß Zink bei vielfältigen biochemischen Vorgängen involviert ist. Vergleichbare Serum-Zinkwerte sind nur dann erhältlich, wenn Nüchternheit, Ruhelage oder konstante Belastung eingehalten werden.
\end{abstract}

\section{Changes in the serum zinc concentration in different metabolic situations}

The concentration of zinc in the serum was measured against time in healthy probands at rest and under bodily stress, after the oral administration of glucose or protein, and after the intravenous injection of glucose or secretin. Zinc was determined by neutron activation analysis and by atomic absorption spectroscopy. The dry weight or protein concentration of the serum was also recorded.

The serum zinc concentration fell during resting, but increased during bodily stress. After glucose administration and especially after protein, the serum zinc concentration was decreased, whereas the injection of secretin was followed by an increase.

The data show that the serum zinc concentration must not be looked upon as a constant value, and that zinc is involved in many biochemical processes. Comparable serum zinc values are only obtained with reference to constant conditions, such as the fasting state between meals, resting state or bodily stress.

Seitdem Raulin (1) erstmals 1869 veröffentlichte, daß Zink für das Wachstum von Aspergillus niger essentiell ist, hat dieses Element in Biologie und Medizin großes Interesse gefunden. Heute weiß man, daß Zink in allen pflanzlichen und tierischen Geweben nachweisbar ist (2). Zahlreiche Metalloenzyme sind inzwischen bekannt, die nicht nur Zink enthalten, sondern auch durch dieses Element biologisch aktiviert werden (2-5).

1961 beschrieben Prasad et al (6) bei Einheimischen in Ägypten und im Iran ein Syndrom, das durch Eisenmangelanämie, Hepatosplenomegalie, Zwergwuchs und Hypogonadismus chrakterisiert war und durch Zinkzufuhr deutlich gebessert werden konnte. Zink gilt seitdem für den Menschen als essentielles Spurenelement.

Zink kann in allen biologischen Proben, sei es Gewebe, Serum oder Harn nachgewiesen werden. Während die Zinkkonzentration nicht nur von Organ zu Organ schwankt, sondern auch innerhalb eines einzelnen, makroskopisch homogenen Organs unterschiedlich ist (7), konnten für das menschliche Blutserum engere Normbereiche ermittelt werden. Aus diesem Grunde bietet sich zur Überprüfung des Zinkgehaltes im menschlichen Organismus das Blutserum an. Mit Hilfe moderner Analy senverfahren, wie der Atomabsorptionsspektroskopie oder der Neutronenaktivierungsanalyse lassen sich reproduzierbare Werte gewinnen. Normalwerte im Serum, die mit diesen Analyseverfahren gemessen wurden, sind in Tabelle 1 zusammengetragen. Diese Tabelle enthält außerdem Werte, die mit der heute kaum mehr gebräuchlichen Dithizon-Methode gemessen wurden.

Signifikante Unterschiede in der Serum-Zinkkonzentration zwischen den Geschlechtern sind nicht nachweisbar $(8,9)$. Dagegen scheint eine deutliche Altersabhängigkeit zu bestehen, ebenso wie eine strenge Korrelation zwischen dem Zink- und Proteingehalt nachgewiesen werden konnte (10).

Im Anschluß an die von Kasperek et al $(18,19)$ berichtete Beobachtung, daß die Serum-Zinkkonzentration nach Einnahme eines standardisierten Frühstücks über einen Zeitraum von 6 Stunden deutlich abnimmt, wurde in den folgenden Versuchen überprüft, welcher Nahrungsbestand teil und welche anderen Faktoren den Zinkgehalt beeinflussen.

\section{Methodik}

Die Zinkkonzentration im Serum wurden mit Hilfe der Atomabsorptionsspektroskopie in Anlehnung an die von Hackley et al (20) beschricbene Methode und mit der instrumentellen Neutronenaktivierungsanalyse $(21)$ ermittelt. Dazu wurden nach Zentrifugieren venös entnommenen Blutes $1 \mathrm{ml}$ Serum für die Atomabsorptionsspektroskopie und $2 \mathrm{ml}$ Serum für 
Tab. 1. Serum-Zink-Konzentration im menschlichen Serum bei verschiedenen Autoren

\begin{tabular}{lll}
\hline Autor & Zink-Konzentration in mg/l & Methode \\
\hline Andrews (8) & $0,80-1,18$ bei Männern & Atomabsorptionsspektroskopie \\
& $0,88-1,22$ bei Frauen & \\
Buddecke (5) & $1,00-1,20$ & nicht angegeben \\
Davies $(9)$ & 0,95 & Atomabsorptionsspektroskopie \\
Giovannetti (12) & 1,01 & Neutronenaktivierungsanalyse \\
Halstead (11) & 0,96 & Atomabsorptionsspektroskopie \\
Kasperek & $1,16 \pm 0,14$ & Neutronenaktivierungsanaly se \\
Parisi (3) & $1,20 \pm 0,20$ & Atomabsorptionsspektroskopie \\
Parr (13) & 0,85 & Neutronenaktivierungsanalyse \\
Sullivan (14) & $0,94 \pm 0,11$ & Atomabsorptionsspektroskopie \\
Vallee (15) & $1,21 \pm 0,19$ & Dithizon \\
Berfenstam (16) & $1,09 \pm 0,20$ & Dithizon \\
Vikbladh (17) & $1,21 \pm 0,15$ & Dithizon \\
\hline
\end{tabular}

die Neutronenaktivierungsanalyse benötigt. Bei beiden Methoden wurde $Z$ ink in $\mu \mathrm{mol} / 1$ Serum bestimmt. Der Ausgangswert wurde gleich $100 \%$ gesetzt, die nachfolgenden Werte wurden auf diesen Wert bezogen.

Bei der Atomabsorptionsspektroskopie wurde anstelle der von Hackley verwendeten Dextranlösung eine Polyvinylpyrrolidonlösung zur Herstellung der Eichlösung benutzt. Aktivierungsanalytisch wurde das langlebige ${ }^{65} \mathrm{Zn}$ in dem bei $110^{\circ} \mathrm{C}$ über $24 \mathrm{~h}$ getrockneten Serum gemessen. Bei den mit der Atomabsorptionsspektroskopie ermittelten $\mathrm{Zn}$-Werten betrug die doppelte Standardabweichung $12 \%$, bei der Neutronenaktivierungsanalyse $8 \%$. Die Serumproteine wurden nach der Biuret-Methode in $\mathrm{g} / \mathrm{l}$ bestimmt.

Belastungsversuche

Alle Messungen begannen um 8.00 Uhr morgens. Bei den Probanden handelte es sich um 24- bis 32jährige, gesunde, nüchterne Personen. Das für die Zinkmessung bestimmte Blut wurde stets aus der Cubitalvene mittels Plastikkanüle und Spritze entnommen.

\section{Ruhe und körperliche Belastung}

Um den möglichen Einfluß von Ruhelage und körperlicher Belastung auf den Serum-Zinkgehalt zu überprüfen, wurden folgende 3 Versuche durchgeführt:

1. Bei 3 Probanden im Alter von 25 bis 29 Jahren wurde Venenblut vor Bettruhe, nach 15 min Ruhelage und nach anschließender Fahrradergometerbelastung über $5 \mathrm{~min} \mathrm{mit}$ $125 \mathrm{~W}$ entnommen.

2. Die Ruhephase wurde bei 3 Probanden im Alter zwischen 22 und 29 Jahren auf 120 min ausgedehnt und anschließend der gleiche Belastungstest durchgeführt. Die Probenentnahme erfolgte vor der Ruhephase, $120 \mathrm{~min}$ nach Ruhebeginn, sowie unmittelbar nach der Ergometerbelastung.

3. Der Einfluß von Ruhelage und gleichzeitiger Dauertropfinfusion mit physiologischer $\mathrm{NaCl}-\mathrm{Lösung}$ wurde bei einer 19jährigen Probandin überprüft, indem vor der Ruhelage und in gleichmäßigen Abständen während der Infusion über 150 min Blut entnommen wurde.

\section{Orale Glucosebelastung}

4 Probanden im Alter zwischen 24 und 32 Jahren erhielten oral je $1 \mathrm{~g}$ Glucose pro kg Körpergewicht, aufgelöst in $500 \mathrm{ml}$ Wasser, das in einem Zeitraum von 3 min zu trinken war. Vor der Glucosebelastung und danach in Abständen von 15 und dann 30 min wurde über einen Zeitraum von 195 min den liegenden Probanden, die eine konstante Infusion mit physiologischer NaCl-Lösung erhielten, venöses Blut entnommen.

\section{Orale Eiweißbelastung}

Eine weitere Gruppe, bestehend aus 2 Männern im Alter von 27 und $29 \mathrm{~J}$ ahren und einer 24jährigen Frau, erhielt oral
$0,5 \mathrm{~g}$ Milcheiweiß ${ }^{1}$ ) pro kg Körpergewicht, aufgelöst in $500 \mathrm{ml}$ Wasser, das innerhalb von 5 min zu trinken war. Die Zeiten der venösen Blutentnahme entsprachen denen bei oraler Glucosebelastung.

\section{Intravenöse Glucosebelastung}

Zum Ausschluß der Frage, ob die beobachteten Veränderungen allein durch Resorptionsmechanismen bedingt waren, wurde 3 Probanden im Alter von 24 bis 29 Jahren bei ansonsten

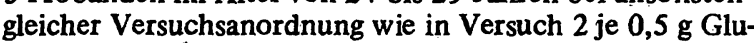
cose pro kg Körpergewicht als $\mathbf{4 0}$ proz. Lösung in einem Zeitraum von $2 \mathrm{~min}$ intravenös injiziert.

\section{Intravenöser Sekretintest}

Zur Überprüfung der Frage, ob die beobachteten Serum-Zinkveränderungen nach Nahrungsaufnahme durch die Aktivierung des exokrinen Pankreas bedingt waren, wurde 2 Probanden im Alter von 29 und 32 Jahren das Enterohormon Sekretin in einer Dosierung von $1 \mathrm{IE}$ pro kg Körpergewicht intravenös injiziert. Die übrige Versuchsanordnung entsprach den vorhergehenden Versuchen.

\section{Ergebnisse}

Der Serum-Zinkgehalt fällt nach 15 Minuten Ruhelage um etwa $10 \%$ ab. Die bei der 2 . Versuchsgnippe erst nach 120 Minuten Ruhelage gemessene Zinkkonzentration stimmt mit dem nach 15 Minuten gemessenen Wert annähernd überein. Die bei Ruhelage mittels intravenösem Dauertropf applizierte physiologische $\mathrm{NaCl}$-Lösung ändert den für die Ruhelage beobachteten Abfall nicht. Nach einer temporären körperlichen Belastung steigt der Zinkgehalt im Serum über den Ausgangswert an, gleichgültig, ob die Belastung im Anschluß an eine 15 minütige oder 120 minütige Ruhelage vorgenommen wurde. Die in allen Versuchen gleichzeitig mitbestimmten Serumproteinwerte zeigten ein paralleles Verhalten zum Serum-Zinkgehalt, d. h., bei Ruhelage fielen sie ab und stiegen nach Fahrradergometerbelastung über den Ausgangswert an; während der $\mathrm{NaCl}$-Infusion nahmen die Proteinwerte parallel mit den Zinkwerten ab.

1) Milcheiweiß K der Fa. Rovianda 
Kontrolluntersuchungen zeigten, daß die Serum-Trockengewichte und die Serum-Proteinwerte innerhalb der Fehlergrenze der Bestimmung ( $\pm 10 \%$ ) gleiche Werte lieferte. Deswegen wurde das Trockengewicht im folgenden als Bezugsgröße des Serum-Zinks gewählt.

Abbildung 1 zeigt die Änderung der mittleren Zink-

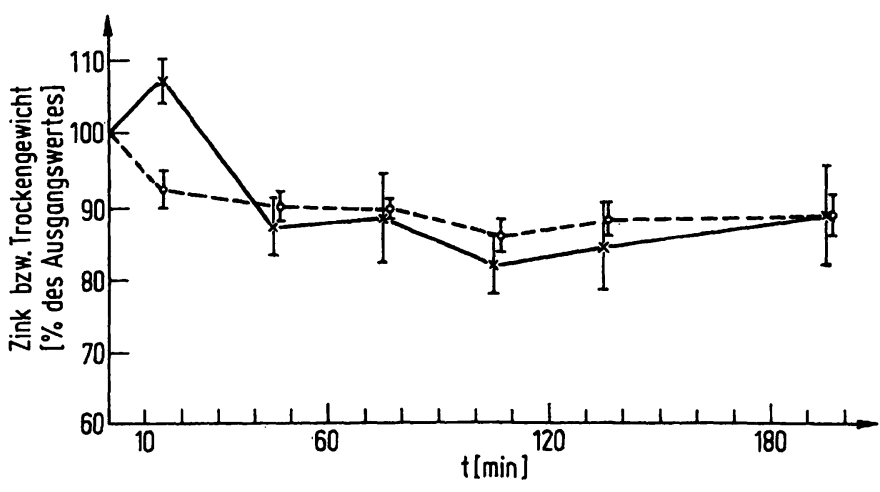

Abb. 1. Zeitliche Änderung der relativen Serumzinkkonzentration $\left(\mathrm{x}-\mathrm{x} ; \overline{\mathrm{x}} \pm s_{\overline{\mathrm{x}}}\right)$ und der entsprechenden Trockengewichte $\left(0-0 ; \bar{x} \pm S_{\bar{x}}\right)$ von Serum nach oraler Zufuhr von $1 \mathrm{~g}$ Glucose pro kg Körpergewicht, aufgelöst in $500 \mathrm{ml}$ Wasser.

konzentration und der Trockengewichte der entsprechenden Einzelproben nach oraler Glucosebelastung. Einem initialen Anstieg der Serum-Zinkkonzentration um 8\% nach 15 Minuten, der mit dem entsprechenden Serumtrockengewicht nicht korreliert ist, folgt ein Abfall um $10-20 \%$ vom Ausgangswert während der nächsten 3 Stunden. Der Unterschied zwischen Zink-Konzentration und Glucosebelastung und nach Ruhelage ist bei 15 Minuten signifikant (im $t-T$ est ist $2 p<0,01$ ). Der niedrigste Zinkwert wird nach 105 Minuten erreicht. Nach einer Versuchszeit von 195 Minuten liegt die mittlere Zink-Konzentration noch $12 \%$ unter dem Ausgangswert. Das Trockengewicht der Einzelproben korreliert bis zu dem 15-Minutenwert mit der gemessenen Zink-Konzentration. Der Unterschied zwischen Trockengewicht und Zink-Konzentration bei 15 Minuten ist signifikant gegenüber den Werten zu den anderen Zeiten (im t-Test ist $2 \mathrm{p}<0,01$ ).

Bei der intravenösen Ǵlucosebelastung fällt der Zinkgehalt bereits nach 10 Minuten auf $75 \%$ des Ausgangswertes (Abb. 2). Die Daten während der folgenden 2,5 Stunden bleiben annähernd konstant. Die zugehörigen Trockengewichte der Einzelproben zeigen ebenfalls einen initialen Abfall, dem ein Plateau folgt. Während des ganzen Versuches sind Zink-Konzentrationswerte und Trockengewichte korreliert.

Nach oraler Proteinzufuhr fällt die Serum-Zinkkonzentration initial schnell und dann mit einer langsameren Rate während eines Zeitraumes von $180 \mathrm{Mi}$ nuten kontinuierlich auf 50-60\% des Ausgangswertes ab (Abb. 3). Das Trockengewicht der Einzelproben verringert sich nach 15 Minuten durchschnittlich um $10 \%$ vom Ausgangswert und bleibt dann ohne wesentliche Änderung während der Versuchsdauer. Bei diesem Versuch korreliert der Zinkwert nicht mit dem entsprechenden Trockengewicht; die Differenz zwischen Zinkgehalt und Trockengewicht bei 195 Minuten ist gegenuber den Werten nach 15 Minuten signifikant (im t-Test ist der $2 \mathrm{p}$-Wert $<0,001$ ).

Abbildung 4 zeigt, daß eine intravenöse Sekretinapplikation einen zweigipfligen Anstieg der Serum-Zink-

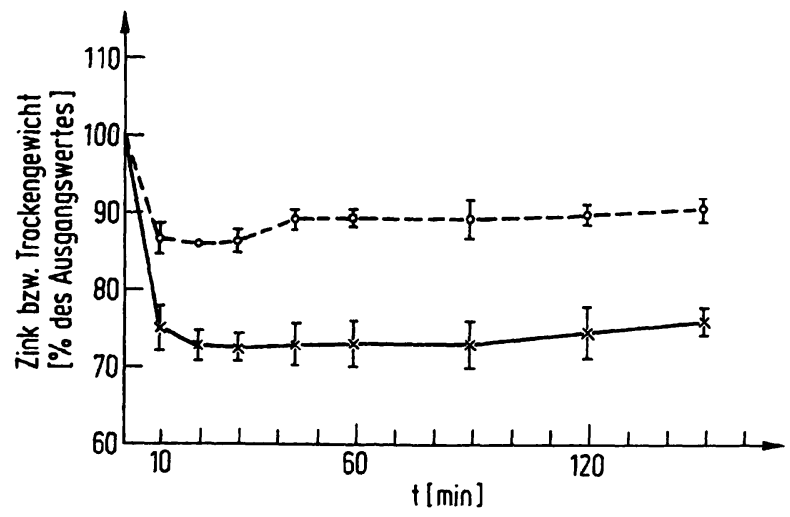

Abb. 2. Zeitliche Änderung der relativen Serumzinkkonzentration $\left(\mathbf{x}-\mathbf{x} ; \overline{\mathbf{x}} \pm s_{\mathbf{x}}\right)$ und der entsprechenden Trockengewichte $(0-0 ; \bar{x} \pm s \bar{x})$ von Serum nach intravenöser Injektion von $0,5 \mathrm{~g}$ Glucose pro $\mathrm{kg}$ Körpergewicht in 40 proz. Lösung.

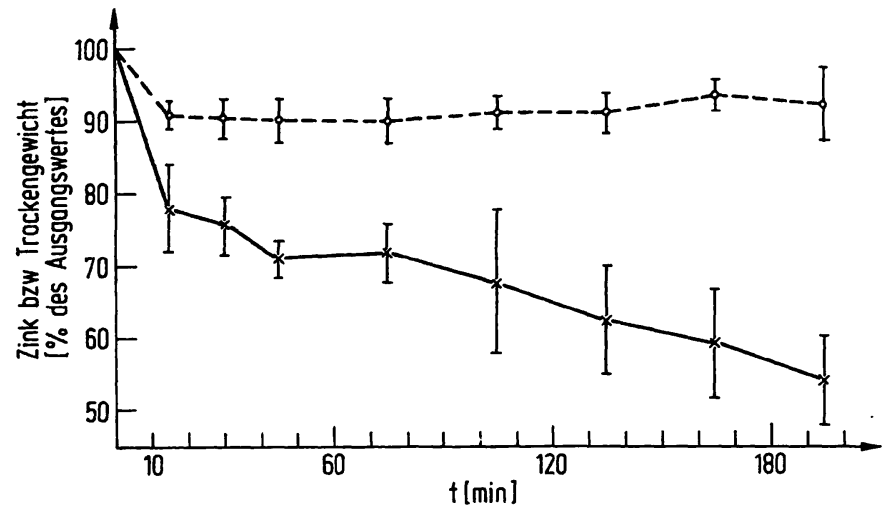

Abb. 3. Zeitliche Änderung der relativen Serumzinkkonzentration $(x-x ; \bar{x} \pm s \bar{x})$ und der entsprechenden Trockengewichte $\left(0-0 ; \overline{\mathbf{x}} \pm s_{\overline{\mathbf{x}}}\right)$ von Serum nach oraler Zufuhr von $0,5 \mathrm{~g}$ Protein pro $\mathrm{kg}$ Körpergewicht, aufgelöst in $500 \mathrm{ml}$ Wasser.

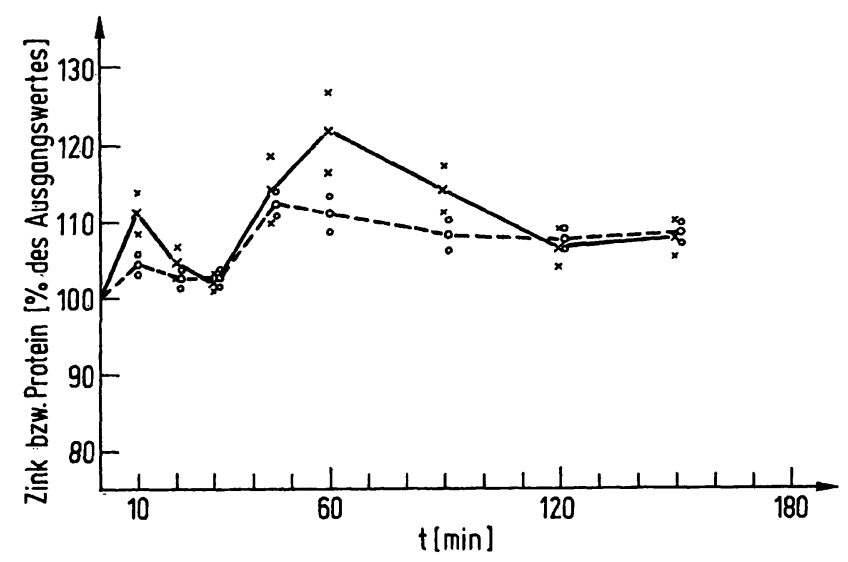

Abb. 4. Zeitliche Änderung der relativen Serumzinkkonzentration $\mathbf{x}-\mathbf{x}$ Mittelwerte, $\mathbf{x}$ Einzelwerte) von Serum und des Serumproteingehalts (o-o Mittelwerte, o Einzelwerte) nach intravenöser Injektion von 1 IE Secretin pro $\mathrm{kg}$ Körpergewicht. 
konzentration verursacht. Nach einem ersten Anstieg um $11 \%$ nach 10 Minuten fallt die Zinkkonzentration annähernd wieder auf den Ausgangswert zurück und erreicht nach 60 Minuten einen erneuten Höchstwert, der $20 \%$ über dem Ruhewert liegt. Die Serum-Proteinwerte zeigen nur angedeutet Gipfel bei 10 und 60 Minuten und verhalten sich im übrigen parallel zu den Zinkkonzentrationen.

\section{Diskussion}

Die vorliegenden Ergebnisse zeigen, daß die Serum-Zinkkonzentration nicht als konstanter Wert betrachtet werden darf. Es ist somit notwendig, bei jeglichen Zinkstoffwechselstudien bestimmte Bedingungen zu beachten. Reproduzierbare Werte, insbesondere bei dynamischen Studien, sind offensichtlich nur dann erhältlich, wenn Nüchternheit des Patienten, die gleiche Tageszeit und Ruhelage über 10 Minuten vor Testbeginn und während des Testes oder eine konstante körperliche Belastung gewährleistet sind.

Der bereits von Kasperek et al $(18,19)$ beschriebene Abfall der Serum-Zinkkonzentration nach Einnahme eines Standardfrühstücks bestätigt sich nach oraler Gabe von Protein. Ein geringerer Abfall wird auch nach Glucosezufuhr beobachtet, wobei der Effekt nach intravenöser Applikation größer ist als nach oraler Verabreichung. Während der Glucose-induzierte Abfall relativ rasch zu einem Plateau führt und mit den SerumTrockengewichten parallel verläuft, korreliert der Proteininduzierte Zinkabfall zu den Serum-Trockengewichten nicht. Der Zinkabfall, der nach Probefrühstück beschrieben wurde $(18,19)$, dürfte ebenfalls durch den enthaltenen Proteinanteil bedingt sein. In beiden Versuchen findet sich eine ähnliche Abnahme der Zinkkonzentration.

Eine temporäre körperliche Belastung bedingt einen innerhalb von Minuten einsetzenden Anstieg der SerumZinkkonzentration, während Ruhelage den Zinkwert verringert. Die initiale Zinkabnahme unter Ruhebedingungen ist durch einen intravasalen Wassereinstrom und den damit verbundenen Verdünnungseffekt erklärbar. Die gleichzeitige Abnahme des Serumproteingehaltes und der gegensinnige Effekt unter körperlicher Belastung sprechen für diese Annahme.

Die orale Glucosebelastung verändert den Serum-Zinkwert bis auf den temporären initialen Anstieg nicht signifikant von den Daten, die bei Ruhelage erhalten werden. Für den Anstieg des Zinkgehaltes nach 15 Minuten findet sich z. Zt. keine Erklärung. Der von Davis et al (9) und Behne und Diel (21) nach 30 bzw. 60 Minuten festgestellte Abfall der Zinkkonzentration nach oraler Glucosebelastung stimmt mit den vorliegenden Daten annähernd überein; allerdings findet sich bei beiden Autoren weder eine Angabe über Zinkkonzentrationsänderungen während der ersten 30 Minuten nach Glucosegabe, noch ein Hinweis über den Zustand der körperlichen
Belastung während der Versuchsdauer. Im Gegensatz zur oralen findet sich nach intravenöser Glucosebelastung sofort ein signifikanter Abfall der Zinkkonzentration im Serum. Wie Davis et al (9) nachwiesen, läßt sich der Abfall nicht nur durch eine Verschiebung der Osmolarität erklären. Ob eine Beziehung zwischen Insulin- und Zinkstoffwechsel besteht (5), bleibt nach den vorliegenden Daten fraglich. Die parallel zu den Zinkmessungen bestimmten Blutzuckerwerte in Versuch 2 und 3 zeigen, daß in beiden Versuchen die Blutzuckerspiegel bereits wieder normale Ausgangswerte erreicht hatten, während die Zinkkonzentrationen 150 und mehr Minuten nach Glucosebelastung noch erniedrigt waren. So lagen nach oraler Glucosezufuhr die Blutzuckerwerte nach 120 Minuten wieder im Normbereich, nachdem sie ein durchschnittliches Maximum bei $45 \mathrm{Mi}$ nuten gezeigt hatten. Nach intravenöser. Glucosezufuhr lagen die Maximalwerte bereits bei 10 Minuten, und 60 Minuten nach Injektion waren die Ausgangswerte wieder erreicht.

Den ausgeprägtesten Abfall der Serum-Zinkkonzentration beobachtet man nach oraler Proteinzufuhr. Dieser Abfall läßt sich, wie aus der fehlenden Korrelation von Serumzinkwert zum Trockengewicht folgt, nicht durch osmotische Mechanismen erklären, vielmehr scheinen zinkabhängige biochemische Vorgänge im Vordergrund zu stehen. Von Bedeutung dürfte dabei u. a. die Aus: schüttung zinkhaltiger Enzyme aus dem Pankreas sein.

Bei isolierter Reizung des Pankreas durch Sekretin findet sich allerdings ein Anstieg der Serum-Zinkkonzentration. Dieser Anstieg läßt sich nicht durch alleinige Resorption der zinkhaltigen Pankreasenzyme erklären, da nach den Daten von Sullivan et al selbst bei maximaler Resorption dieser Enzyme lediglich eine Erhöhung der Serum-Żinkkonzentration um 5\% resultieren dürfte. Offenbar müssen weitere zinkhaltige Enzyme involviert oder Zink aus einem bislang nicht bekannten Pool freigesetzt werden. Die Schnelligkeit der beobachteten Konzentrationsänderungen des Serum-Zinkspiegels lassen es nicht wahrscheinlich erscheinen, daß eine Änderung des zellulären Stoffwechsels hier ihren Ausdruck findet, obwohl enge Beziehungen von Zink zum Nucleinsäure- und Proteinstoffwechsel gefunden wurden (24-26).

Zink und Trockengewicht korrelieren im Gegensatz zur Glucose-Zufuhr nach Proteinernährung nicht. Da Zink im Serum zu 98\% an Protein gebunden ist, stellt sich hier die Frage, wohin das freigesetzte Zink aus dem peripheren Blut wandert. Eine Antwort auf diese Frage dürfte dazu beitragen, die metabolische Bedeutung dieses Spurenelementes weiter zu klären.

\section{Danksagung}

Die Autoren danken für die effiziente technische Hilfe von Frau G. Kozlowski, Frau M. Wiesen, Herrn V. Siller und Herrn M. Dresbach. 


\section{Literatur}

1. Raulin, J., (1869), Ann. Sci. Natl. Botan. Biol. Végétale 11, 93-299.

2. Prasad, A. S. (1967), Fed. Proc. 26, 172-185.

3. Parisi, A. F. \& Vallee, B. L. (1969), Amer. J. Clin. Nutr. $22,1222-1239$.

4. Bowen, J. M. (1972), The biochemistry of the trace elements. Paper SM 157/83, IAEA Symposium Bled.

5. Buddecke, E. (1971), Grundriß der Biochemie. 2. Aufl. Verlag Walter de Gruyter \& Co., Berlin.

6. Prasad, A. S., Halstead, J. A. \& Nadimi, M. (1961), Am. J. Med. 31, 532-546.

7. Schicha, H., Kasperek, K., Feinendegen, L. E., Siller, V. \& Klein, H. J. (1972), Beitr. Path. 146, 55-62.

8. Andrews, G. S. (1971), Exfoliative Cytology, Verlag Charles C. Thomas, Springfield.

9. Davies, I. J. T., Musa, M. \& Domandy, T. L. (1968), J. Clin. Nutr. 21, 359-365.

10. Giovannetti, S., Maggiore, Q. \& Malvano, R. (1967), Paper SM 91/5, IAEA Symposium Amsterdam.

11. Halstead, J. A. \& Smith, J. C. (1970), Lancet I, 322-324.

12. Kasperek, K., Schicha, H., Siller, V. \& Feinendegen, L. E. (1972), Strahlentherapie 143, 468-472.

13. Parr, R. M. \& Taylor, D. M. (1964), Biochem. J. 91, 424431.

14. Sullivan, J. F. \& Heaney, R. P. (1970), Am. J. Clin. Nutr. $23,170-177$.
15. Vallee, B. L., Wacker, W. E. C., Bartholmey, A. F. \& Hoch, F. U. (1959), Ann. Intern. Med. 50, 1077-1091.

16. Berfenstam, R. (1952), Acta Paediat. (Stockholm) 41, Suppl. 87, 3-24.

17. Vikbladh, I. (1950), Scand. J. Clin. Lab. Invest. 2, 143148.

18. Kasperek, K., Schicha, H., Siller, V., Höck, A. \& Feinendegen, L. E. (1973), Strahlentherapie 145, 229-232.

19. Kasperek, K., Schicha, H., Siller, V. \& Feinendegen, L. E. (1972), Paper SM 157/35, IAEA Symposium Bled.

20. Hackley, B. M., Smith, J. C. \& Halstead, J. A. (1968), Clin. Chem. 14, 1-5.

21. Kasperek, K. (1969), ATKe 14-22. 143-146.

22. Behne, D. \& Diel, F. (1972), Paper SM 157/11, IAEA Symposium Bled.

23. Sullivan, J. F., O’Grady, J. \& Lankford, H. G. (1965), Gastroenterology 48, 438-443.

24. Underwood, E. F. (1970), in Trace element metabolism in animals (Mills, C. F., Hrsg.), E \& S Verlag, Livingstone, S. 5-21.

25. Williams, R. B. \& Chesters, J. K. (1970), Trace element metabolism in animals (Mills, C. F., Hrsg.), E \& F Verlag, Livingstone, S. 164-166.

26. Sandstead, H. H., Burk, F. R., Booth, G. H. \& Darby, W. J. (1970), Med. Clin. North. Amer. 54, 1509-1531.

Dr. Manfred Persigehl Institut für Medizin der Kernforschungsanlage Jülich $\mathrm{GmbH}$ 517 Jülich, Postfach 365 